\title{
Activation of Src signaling mediates acquired resistance to ALK inhibition in lung cancer
}

\author{
RYOHEI YOSHIDA $^{1}$, TAKAAKI SASAKI ${ }^{1}$, YOSHINORI MINAMI $^{1}$, YUKIKO HIBINO $^{1}$, \\ SHUNSUKE OKUMURA ${ }^{1}$, MASATOSHI SADO ${ }^{2}$, NAOYUKI MIYOKAWA ${ }^{2}$, \\ SATOSHI HAYASHI ${ }^{1}$, MASAHIRO KITADA ${ }^{1}$ and YOSHINOBU OHSAKI ${ }^{1}$
}

${ }^{1}$ Respiratory Center, ${ }^{2}$ Department of Pathology, Asahikawa Medical University, Asahikawa, Hokkaido 078-8510, Japan

Received May 23, 2017; Accepted September 4, 2017

DOI: 10.3892/ijo.2017.4140

\begin{abstract}
Anaplastic lymphoma kinase (ALK) fusion oncogenes occur in approximately 3-5\% of non-small cell lung cancer (NSCLC) cases. Various ALK inhibitors are in clinical use for the treatment of ALK-NSCLC, including the first generation ALK inhibitor, crizotinib, and recently the more highly potent alectinib and ceritinib. However, most tumors eventually become resistant to ALK specific inhibitors. To address the mechanisms underlying the development of ALK inhibitor resistance, we used iTRAQ quantitative mass spectrometry and phosphor-receptor tyrosine kinase arrays to investigate intracellular signaling alterations in ALK inhibitor resistant NSCLC cell lines. Src signaling was identified as an alectinib resistance mechanism, and combination treatment with ALK and Src inhibitors was highly effective for inhibiting the growth of ALK inhibitor resistant cells in vitro and in mouse xenograft models. Furthermore, phospho-receptor tyrosine kinase activation and downstream PI3K/AKT signaling was effectively blocked by inhibiting $\mathrm{Src}$ in alectinib resistant cells. Finally, we showed that the combined use of ALK and Src inhibitors inhibited the growth of other ALK-NSCLC cell lines, including those that were ceritinib or lorlatinib resistant. Our data suggest that targeting Src signaling may be an effective approach to the treatment of ALK-NSCLC with acquired resistance to ALK inhibitors.
\end{abstract}

\section{Introduction}

Lung cancer is the most common cause of cancer mortality, with 1.6 million deaths annually $(1,2)$. Non-small cell lung cancers (NSCLCs) are currently sub-classified based on the presence of actionable driver oncogenes, and molecular

Correspondence to: Dr Takaaki Sasaki, Respiratory Center, Asahikawa Medical University, 2-1-1-1 Midorigaoka-Higashi, Asahikawa, Hokkaido 078-8510, Japan

E-mail: takaaki6@asahikawa-med.ac.jp

Key words: Src, drug resistance, ALK inhibitors, non-small cell lung cancer targeted therapies have been developed to specifically treat cancers harboring these driver mutations (3). Anaplastic lymphoma kinase (ALK) inhibitors are clinically effective for the treatment of NSCLC patients whose tumors harbor ALK fusion genes, including the echinoderm microtubule-associated protein-like 4 (EML4) - $A L K$ fusion (EML4-ALK) (4).

The first generation ALK inhibitor, crizotinib, can elicit dramatic and durable responses in ALK-NSCLCs (5). In the last few years, alectinib and ceritinib have been developed for the treatment of ALK-NSCLCs $(6,7)$. Unfortunately, the development of resistance to ALK inhibitors is common and arises through a variety mechanisms $(8,9)$. One of the most important of these mechanisms is the activation of alternative survival pathways, including EGFR, MET, cKIT and IGFR signaling (10). Although activation of Src tyrosine kinase signaling is linked to crizotinib resistance, this survival pathway was not linked to the development of resistance to other ALK inhibitors $(11,12)$.

Heat shock protein (Hsp) 90 inhibitors are effective for the treatment of ALK-NSCLC (13). Hsp90 is a major intracellular molecular chaperone that interacts with a wide variety of intracellular proteins, and promotes correct protein folding and conformation. Hsp90 client proteins include many important regulators of cell proliferation and differentiation, such as protein kinases and steroid hormone receptors. Hsp90 expression is increased in many cancers, including ALK-NSCLCs. Hsp90 inhibitors promote ALK degradation, and are clinically effective for the treatment of patients with tumors carrying ALK rearrangements, regardless of resistance to ALK inhibitors $(14,15)$.

The aims of the present study were to clarify the mechanisms underlying resistance to ALK specific inhibitors in NSCLC, and identify novel targets that may ultimately form the basis for the design of more effective therapies for overcoming acquired resistance.

\section{Materials and methods}

Cell culture and compounds. The H3122 (EML4-ALK variant 1) NSCLC cell line was kindly provided by Dr Pasi A. Jänne at Dana-Farber Cancer Institute (Boston, MA, USA). H2228 (EML4-ALK variant 3) cells were purchased from the 
American Type Culture Collection (ATCC; Manassas, VA, USA) and maintained at $37^{\circ} \mathrm{C}$ in $5 \% \mathrm{CO}_{2}$ using RPMI-1640 medium (Thermo Fisher Scientific, Waltham, MA, USA) containing $2 \mathrm{mM}$ L-glutamine, $50 \mathrm{U} / \mathrm{ml}$ penicillin, and $50 \mu \mathrm{g} / \mathrm{ml}$ streptomycin, supplemented with $10 \%$ fetal bovine serum (FBS) (R-10 medium). Alectinib was provided by Chugai Pharmaceutical Co., Ltd., (Kamakura, Japan) and AUY922 was provided by Novartis Pharma AG (Basel, Switzerland). Ceritinib, lorlatinib, saracatinib, dasatinib and bosutinib were purchased from Selleck Chemicals (Houston, TX, USA). Each compound was dissolved in dimethyl sulfoxide (DMSO; Wako Pure Chemical Industries, Ltd., Tokyo, Japan) for cell culture experiments.

Generation of H3122-AFR, H3122-LDKR and H3122-PFR cell lines. $\mathrm{H} 3122$ cells were treated with alectinib at a starting concentration of $1 \mathrm{nM}$ and cells were maintained at $\sim 70 \%$ confluence. After every passage at a given concentration of drug, the concentration of alectinib was increased until a final concentration of $100 \mathrm{nM}$ was achieved. The resulting pool of resistant cells (designated H3122-AFR) was maintained in R-10 medium containing $100 \mathrm{nM}$ alectinib. Other ALK inhibitor resistant cell lines were established in a similar manner. The H3122 derivatives, H3122-LDKR and H3122-PFR, were maintained in R-10 medium with $1 \mu \mathrm{M}$ ceritinib or $100 \mathrm{nM}$ lorlatinib, respectively.

Cell growth assays. For MTS assays, $3-4 \times 10^{3}$ cells were plated into 96-well plates. After $24 \mathrm{~h}$, cells were treated with drugs, and incubated for a further $72 \mathrm{~h}$. CellTiter $96^{\circledR} \mathrm{AQ}_{\text {ueous }}$ solution (Promega, Maddison, WI, USA) was then added and plates were incubated for an additional $4 \mathrm{~h}$. Optical density was measured at $490 \mathrm{~nm}$ and the data were graphically displayed using GraphPad Prism version 6.0 (GraphPad Software, Inc., La Jolla, CA, USA).

For colony formation assays, $5.0 \times 10^{4}$ cells were plated into 6-well plates and treated with drugs $24 \mathrm{~h}$ later. After 6 days, the media containing drugs were refreshed. One week after media replacement, plates were washed with phosphatebuffered saline (PBS) once, and stained with $500 \mu \mathrm{l}$ of $0.5 \%$ crystal violet with $25 \%$ methanol for $1 \mathrm{~h}$ and photographed.

Immunoblot analysis. Cells grown under the previously specified conditions were lysed in cell lysis buffer (Wako Pure Chemical Industries) with PhosSTOP Phosphatase inhibitor cocktail (Roche, Basel, Switzerland) and Complete EASYPack (Roche). After cell lysis, lysates were centrifuged at 14,000 x g for $10 \mathrm{~min}$ at $4^{\circ} \mathrm{C}$ and the supernatant was used for subsequent procedures. Western blot analyses were conducted after protein separation by SDS-PAGE electrophoresis and transfer to Immobilon-P membrane (Merck KGaA, Darmstadt, Germany). Immunoblotting was performed according to the antibody manufacturer's recommendations. Antibodies against phospho-ALK (\#4144), ALK (\#3633), phospho-EGFR (\#3777), EGFR (\#4267), phospho-Src (\#6943), Src (\#2109), phospho-AKT (\#4060), AKT (\#9272), phosho-P130Cas (\#4011), P130Cas (\#13846), phospho-CrK II (\#3491), CrK II (\#3492), phospho-CrKL (\#3181), CrKL (\#3182), phosphoPaxillin (\#2541), phosphor-FAK (\#3283), FAK (\#3285), pan-phospho-Tyrosine (P-Tyr-100) (\#9411) and $\beta$-actin (\#4967) were purchased from Cell Signaling Technology (Danvers, MA, USA).

Immunofluorescence/immunocytochemistry. A total $5 \times 10^{4}$ of H3122-AFR cells were plated in 8 -well chamber slides 1 day before the drug treatment. The cells were fixed with $2 \%$ paraformaldehyde at room temperature $8 \mathrm{~h}$ after drug treatment. The fixed cells were incubated with primary P-Tyr-100 and Src antibodies diluted in PBS containing 0.5\% Block Ace (DS Pharma Biomedical, Osaka, Japan) for 1 day. After washing with PBS, the fixed cells were incubated with appropriate secondary antibodies conjugated to Alexa dye 488 or 594 (Thermo Fisher Scientific) for $1 \mathrm{~h}$ before mounting. Nuclei were counterstained with DAPI. The images were taken using an Olympus FluoView FV1000 confocal laser scanning microscope, and analyzed with Olympus FluoView ver4.2a Viewer software.

Phospho-receptor tyrosine kinase (RTK) array analysis. A PathScan RTK Signaling Antibody Array kit (Cell Signaling Technology) was used to profile relative tyrosine phosphorylation levels. A total of $2 \times 10^{2}$ cells was seeded in $10-\mathrm{cm}$ dishes 1 day before drug treatment with alectinib and saracatinib, and the cells were harvested 1 day after drug treatment. Phospho-RTK array analysis was performed according to the manufacturer's protocol. The average pixel densities of duplicate spots were determined using ImageJ software (http:// imagej.nih.gov/ij/) and phospho-RTK percentages were calculated relative to the average control intensity.

Next-generation sequencing. Genomic DNA from H3122-AFR cells was isolated using the DNeasy Blood \& Tissue kit (Qiagen) according to the manufacturer's protocol. Ion AmpliSeq Comprehensive Cancer Panel (Thermo Fisher Scientific), a previously validated panel for targeted amplicon sequencing was utilized (Thermo Fisher Scientific). Briefly, $10 \mathrm{ng}$ of gDNA was amplified by PCR using Ion AmpliSeq Library kit (Thermo Fisher Scientific) and the sequencing was performed on an Ion PGM System according to the manufacturer's protocol. Sequencing reads were multiplexed, quality-filtered and aligned to the human reference genome (GRCh37) using the Torrent Suite software (ver. 5.0.4; Thermo Fisher Scientific). Variants were identified with the Variant Caller software (ver. 5.0.4.0; Thermo Fisher Scientific). The quality of all variants called was manually confirmed by Integrative Genomics Viewer software (IGV; ver. 2.3.59).

Xenograft studies. All mouse xenograft experiments were performed using age matched 8-12 week-old female $\mathrm{Nu} / \mathrm{Nu}$ mice. After subcutaneous injection of $5.0 \times 10^{6} \mathrm{H} 3122-\mathrm{AFR}$ cells, mice were randomized into four groups, and treated with either vehicle, alectinib alone, saracatinib alone, or a combination of the two, for the indicated duration of treatment. Tumor size was measured by calipers twice a week. Tumor volume was calculated as length $\mathrm{x}$ width ${ }^{2} \mathrm{x} 0.51$. Treatment was initiated when tumors exceeded $100 \mathrm{~mm}^{3}$. Nude mice bearing H3122-AFR xenografts were treated with vehicle only (Control, $\mathrm{n}=11)$, alectinib (20 mg/kg, $\mathrm{n}=10)$, saracatinib (50 mg/kg, n=11), combination (alectinib $20 \mathrm{mg} / \mathrm{kg}+$ saracatinib $50 \mathrm{mg} / \mathrm{kg}, \mathrm{n}=9$ ) for the indicated number of days. 
A

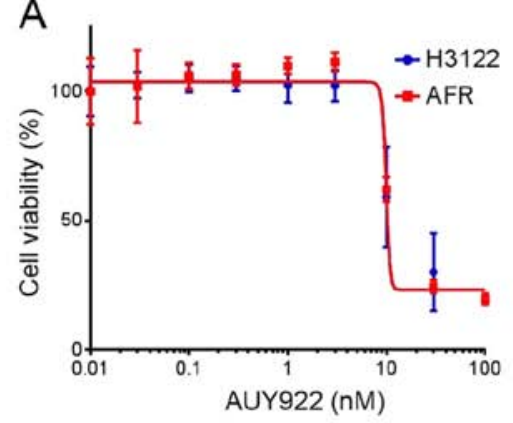

B

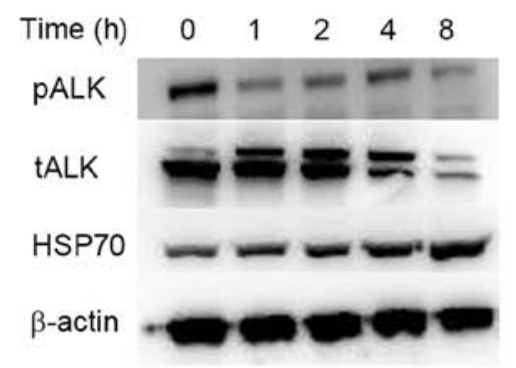

C

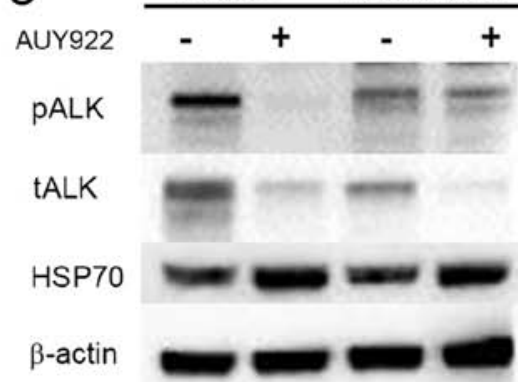

Figure 1. Sensitivity to the Hsp90 inhibitor, AUY922. (A) Sensitivity to the Hsp90 inhibitor, AUY922. H3122 and H3122-AFR cells were grown in 96-well plates and treated with AUY922 at the indicated concentrations. Cell growth was measured after $72 \mathrm{~h}$ by MTS assay. (B) Western blot analysis of H3122-AFR cells showing the effects of AUY922 on the expression of indicated proteins. Cells were treated with AUY922 (100 nM) for the indicated times. (C) Western blot analysis of H3122 and H3122-AFR cells showing the effects of AUY922 on the expression of the indicated proteins. Cells were treated with AUY922 $(100 \mathrm{nM})$ for $4 \mathrm{~h}$.

Each drug was prepared in the following solvents: alectinib (0.02 N HCl, 10\% DMSO, 10\% CremophrEL, 15\% PEG400, $15 \%$ HPCD), saracatinib (0.5\% HPMC and 0.1\% Tween-80). Alectinib was administered by oral gavage and saracatinib was administered by intraperitoneal injection.

iTRAQ sample preparation and analysis. Protein samples were diafiltrated, reduced, alkylated and trypsin digested according to the iTRAQ protocol (Thermo Fisher Scientific). The samples were then labeled using the iTRAQ reagents. Peptides were desalted on a Strata-X $33 \mu \mathrm{m}$ polymeric reversed phase column (Phenomenex, Inc., Torrance, CA, USA) and

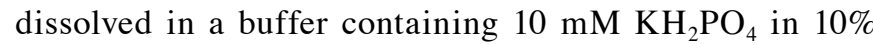
acetonitrile before separation by strong cation exchange liquid chromatography on an Agilent 1100 HPLC system. Peptides were eluted with a linear gradient of 0-400 $\mathrm{mM} \mathrm{KCl}$. Eight fractions containing the peptides were collected and desalted on Strata-X columns. The fractions were analyzed by electrospray ionization mass spectrometry using the Agilent 1260 Infinity HPLC system (Agilent Technologies, Santa Clara, CA, USA) coupled to an Agilent 1260 Chip Cube nanospray interface (Agilent Technologies) on an Agilent 6540 mass spectrometer (Agilent Technologies).

Data analysis was performed according to a previous report (16). Spectral data for each sample were compared against the Swiss-Prot database with taxonomy set to Homo sapiens using ProteinPilot ${ }^{\mathrm{TM}} 4.5$ software (AB Sciex, Redwood City, CA, USA). Average ratios were calculated by comparing the intensities of the peptide signals before and after drug treatment. A P $\leq 0.05$ indicates statistically significant differential expression.

Statistical analysis. The measurements are presented as means \pm SEM. Results were analyzed by the Student's t-test using GraphPad Prism version 6.0 (GraphPad Software). $\mathrm{P}<0.05$ were considered to be statistically significant.

\section{Results}

Generation of ALK lung cancer cell line resistance models. We generated ALK inhibitor resistant lung cancer cell lines by exposing H3122 cells to increasing doses of the alectinib, ceritinib and lorlatinib. The alectinib resistant $\mathrm{H} 3122$ cell line derivative was designated as H3122-AFR. The gDNA extracted from H3122-AFR cells was sequenced using Nextgeneration sequencing but secondary ALK mutation was not found. Ceritinib and lorlatinib resistant H3122 cell line derivatives were designated as H3122-LDKR and H3122-PFR, respectively.

Sensitivity of HSP9O inhibitor inH3122 and H3122-AFR. $\mathrm{H} 3122$ and H3122-AFR cell lines had the same sensitivity to AUY922, and ALK protein expression in H3122-AFR cells was inhibited $4 \mathrm{~h}$ after the addition of AUY922 (Fig. 1A and B). Immunoblotting analysis of $\mathrm{H} 3122$ and H3122-AFR before and after AUY922 treatment for $4 \mathrm{~h}$ revealed that ALK proteins were degraded in both cell lines. However, the expression of Hsp70 proteins was increased in both H3122 and H3122-AFR after AUY922 treatment, consistent with a compensatory activation of co-chaperones in response to Hsp90 inhibition (Fig. 1C).

Chaperone peptides/protein screening in ALK resistant cell lines. As we previously reported (17), the treatment of H3122 cells with Hsp90 inhibitors resulted in the degradation of ALK proteins and the induction of apoptosis, which suggested that growth/survival signaling in these cells was dependent on chaperone activity. To address this hypothesis, we screened for Hsp90 client proteins in H3122 cells before and after the addition of the Hsp90 inhibitor, AUY922. Similarly, proteins/ peptides extracted from H3122-AFR cells were analyzed before and after treatment with AUY922 to study the changes of client proteins after acquired resistance.

For chaperone peptides/protein screening, we analyzed protein expression in $\mathrm{H} 3122$ and H3122-AFR cells in response to AUY922 treatment by iTRAQ quantitative mass spectrometry $(16,18)$. iTRAQ detected 1154 proteins/peptides in each cell line, including 72 candidate proteins in $\mathrm{H} 3122$, and 63 candidate proteins in $\mathrm{H} 3122-\mathrm{AFR}$ that had $\mathrm{P} \leq 0.05$. There were 14 candidate proteins that were common to both $\mathrm{H} 3122$ and H3122-AFR (Fig. 2A). The candidate proteins in the iTRAQ data were converted to gene lists in DAVID (Database for Annotation, Visualization and Integrated Discovery, https:// david.ncifcrf.gov). KEGG (Kyoto Encyclopedia of Genes and 
A

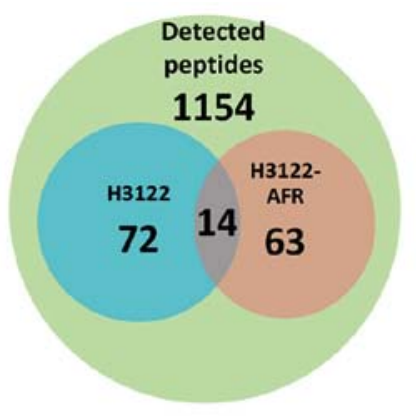

B

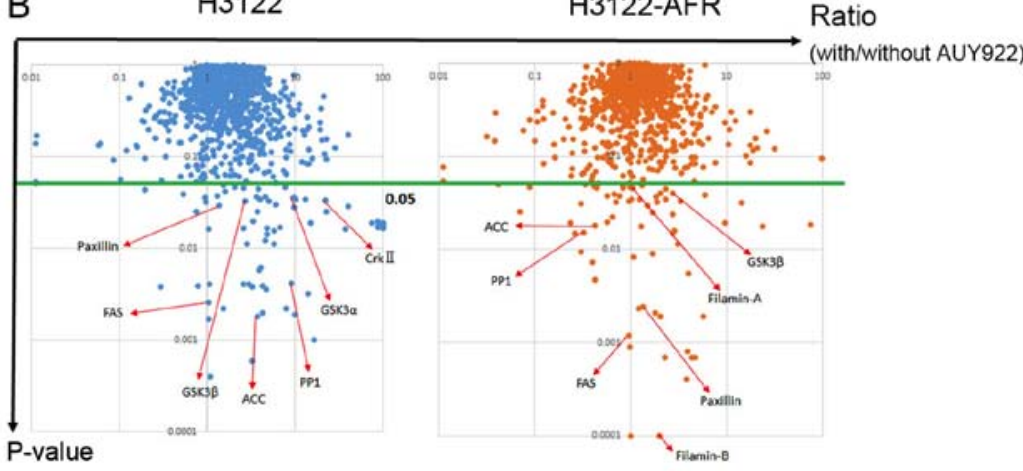

C

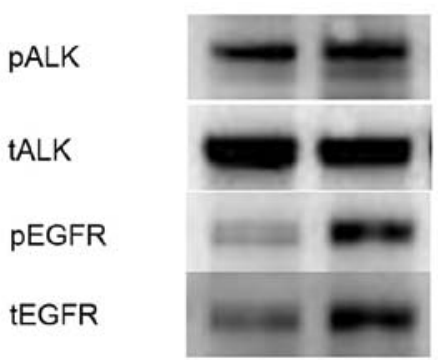

pSrc (Tyr416)

tSrc

pCrkll

pPaxillin

$\beta$-actin
H3122 H3122-AFR

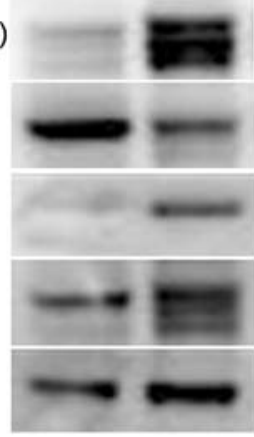

Figure 2. iTRAQ screening for chaperone peptides/proteins in ALK resistant cell lines. (A) Seventy-two candidate proteins that had P $<0.05$ were identified in H3122, 63 candidate proteins were detected in H3122-AFR, and 14 proteins were common to both cell lines. (B) KEGG pathway analysis. The focal adhesion pathway and the insulin signaling pathway were implicated in ALK resistance in H3122 and H3122-AFR cells. (C) Western blot analysis of H3122 and H3122-AFR cells. Expression of ALK and Src and key components of the EGFR and focal adhesion pathways were assessed.

Table I. Analysis of intracellular signaling pathway based on iTRAQ.

\begin{tabular}{|c|c|c|c|c|}
\hline \multirow[b]{2}{*}{ Pathway/proteins } & \multicolumn{2}{|c|}{ H3122 ratio } & \multicolumn{2}{|c|}{ H3122-AFR ratio } \\
\hline & Treated/untreated & P-value & Treated/untreated & P-value \\
\hline \multicolumn{5}{|l|}{ Focal adhesion } \\
\hline Filamin-A & 1.00 & 0.99 & $1.04^{\mathrm{a}}$ & $0.05^{\mathrm{a}}$ \\
\hline Filamin-A & 1.33 & 0.66 & $2.00^{\mathrm{a}}$ & $0.0001^{\circ}$ \\
\hline Paxillin & $1.36^{\mathrm{a}}$ & $0.03^{\mathrm{a}}$ & $1.36^{\mathrm{a}}$ & $0.002^{\mathrm{a}}$ \\
\hline Crk II & $22.28^{\mathrm{a}}$ & $0.03^{\mathrm{a}}$ & 0.34 & 0.70 \\
\hline Crk L & 0.99 & 0.91 & 0.98 & 0.33 \\
\hline MLCP & 1.13 & 0.79 & 1.19 & 0.72 \\
\hline GSK3 $\beta$ & $2.70^{\mathrm{a}}$ & $0.03^{\mathrm{a}}$ & $2.75^{\mathrm{a}}$ & $0.04^{\mathrm{a}}$ \\
\hline GSK $3 \alpha$ & $9.82^{\mathrm{a}}$ & $0.04^{\mathrm{a}}$ & 0.85 & 0.12 \\
\hline Actinib & 3.25 & 0.6 & 1.43 & 0.59 \\
\hline \multicolumn{5}{|c|}{ Insulin signaling pathway } \\
\hline FAS & $1.03^{\mathrm{a}}$ & $0.003^{\mathrm{a}}$ & $0.96^{\mathrm{b}}$ & $0.001^{\mathrm{b}}$ \\
\hline PP1 & $9.12^{\mathrm{a}}$ & $0.004^{\mathrm{a}}$ & $0.32^{\mathrm{b}}$ & $0.015^{\mathrm{b}}$ \\
\hline $\mathrm{ACC}$ & $3.7^{\mathrm{a}}$ & $0.002^{\mathrm{a}}$ & $0.42^{\mathrm{b}}$ & $0.018^{\mathrm{b}}$ \\
\hline
\end{tabular}

Ratio $>1, \mathrm{P}<0.05$; ${ }^{\mathrm{R}}$ atio $<1, \mathrm{P}<0.05$.

Genomes, http://www.genome.jp/kegg/) intracellular pathway analysis of the DAVID gene lists revealed two deregulated signaling cascades, including the focal adhesion pathway and the insulin signaling pathway (Fig. 2B and Table I). Activation of the focal adhesion pathway, involving paxillin and crkII could be an alectinib resistance mechanism. Immunoblotting revealed that H3122-AFR cells had higher phosphoryla- tion levels of paxillin, crkII and Src compared with H3122 cells (Fig. 2C). Taken together, these data suggested that these pathways could be associated with resistance mechanisms.

Activation of Src signaling mediates acquired resistance to alectinib in H3122-AFR cells. Src was reported to confer resistance to crizotinib, but not alectinib in a cell line-derived 


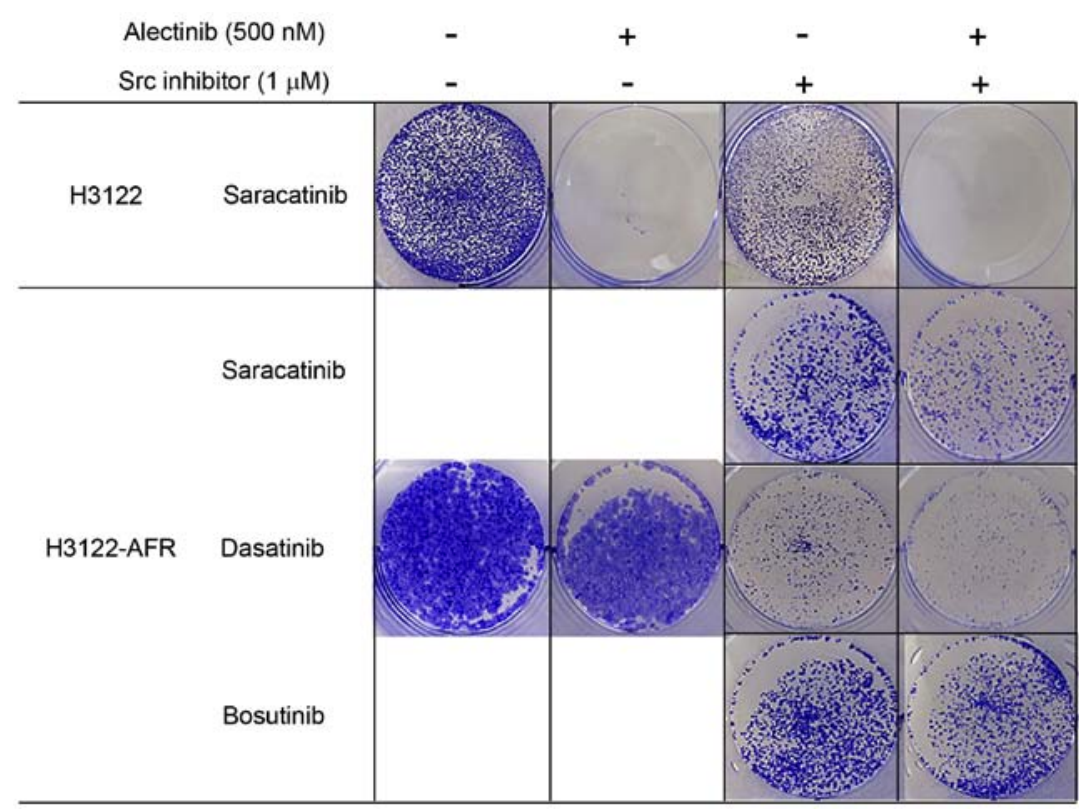

Figure 3. Activation of Src mediates acquired resistance to alectinib in H3122-AFR cells. Colony formation assays addressing the effect of combined treatment with alectinib $(500 \mathrm{nM})$ or Src inhibitors $(1 \mu \mathrm{M})$ alone or in combination on H3122 and H3122-AFR cells.

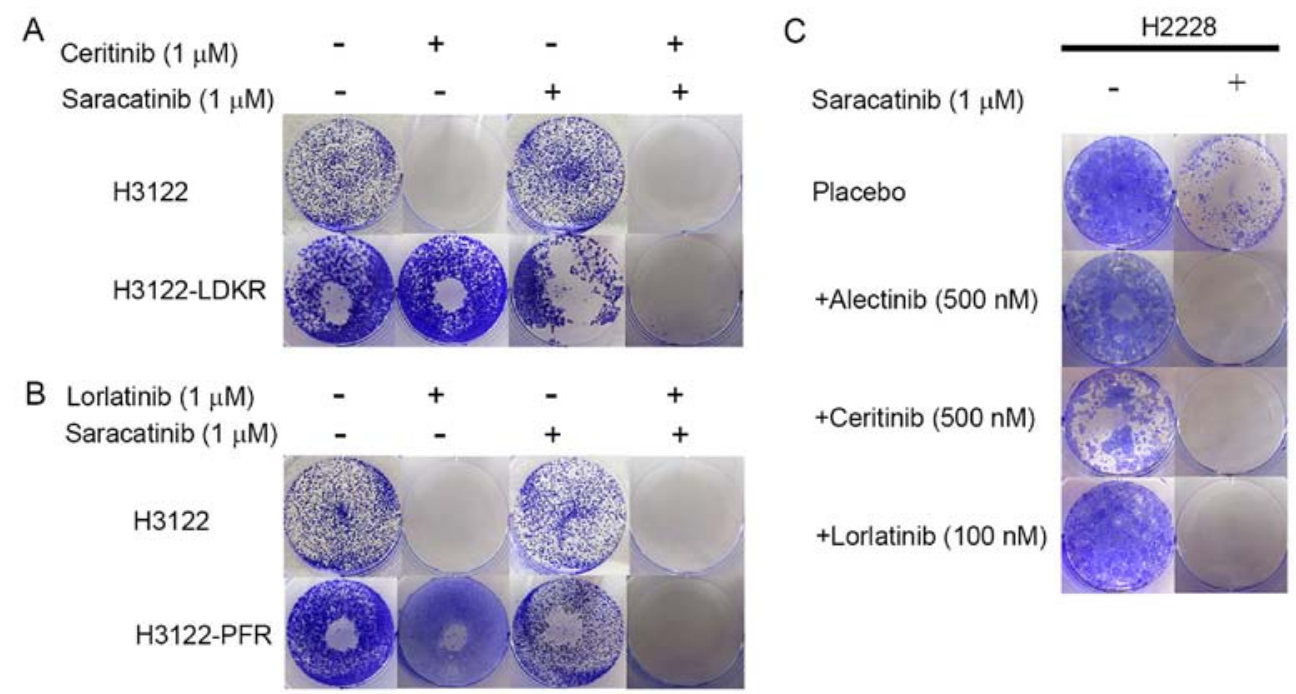

Figure 4. The combined effect of ALK and Src inhibitors on other cell lines. (A and B) Colony formation assays. The indicated cell lines were treated with ceritinib $(500 \mathrm{nM})$ or lorlatinib $(500 \mathrm{nM})$ and/or saracatinib $(1 \mu \mathrm{M})$. (C) H2228 cells were treated with the ALK-inhibitors, alectinib (500 nM), ceritinib $(500 \mathrm{nM})$ and lorlatinib $(100 \mathrm{nM})$ alone or with saracatinib $(1 \mu \mathrm{M})$.

model and resistant cancer cell lines derived from ALK TKI-resistant patients (11).

We hypothesized that the Src protein could be a therapeutic target in H3122-AFR. To test this hypothesis, Src phosphorylation was inhibited with the Src inhibitor, saracatinib. In colony formation assays, the growth of H3122-AFR cells was inhibited more potently by combined treatment with alectinib and saracatinib, compared with alectinib or saracatinib alone (Fig. 3). When H3122-AFR cells were treated with the other Src inhibitors, dasatinib or bosutinib, tumor growth was also inhibited with each compound alone (Fig. 3). These in vitro data are consistent with the therapeutic potential of Src inhibitors for combatting resistance to ALK inhibitors.
Dual blockade of ALK and phospho-Src in other ALK resistant cells. To study whether activation of Src signaling is a mechanism of acquired resistance to ceritinib or lorlatinib, we employed colony formation assays to confirm the combined effects of each ALK inhibitor and saracatinib. In the H3122LDKR and H3122-PFR cell lines, dual blockade of ALK and phosphor-Src inhibited tumor growth more effectively compared with each ALK inhibitor alone, or saracatinib alone (Fig. 4A and B).

The H2228 cell line is resistant to ALK TKIs compared with the H3122 cell line due to pre-existing activation of EGFR signaling (data not shown). Colony formation assays showed that combined treatment with each ALK inhibitor and saracatinib effectively inhibited H2228 cell growth (Fig. 4C). 

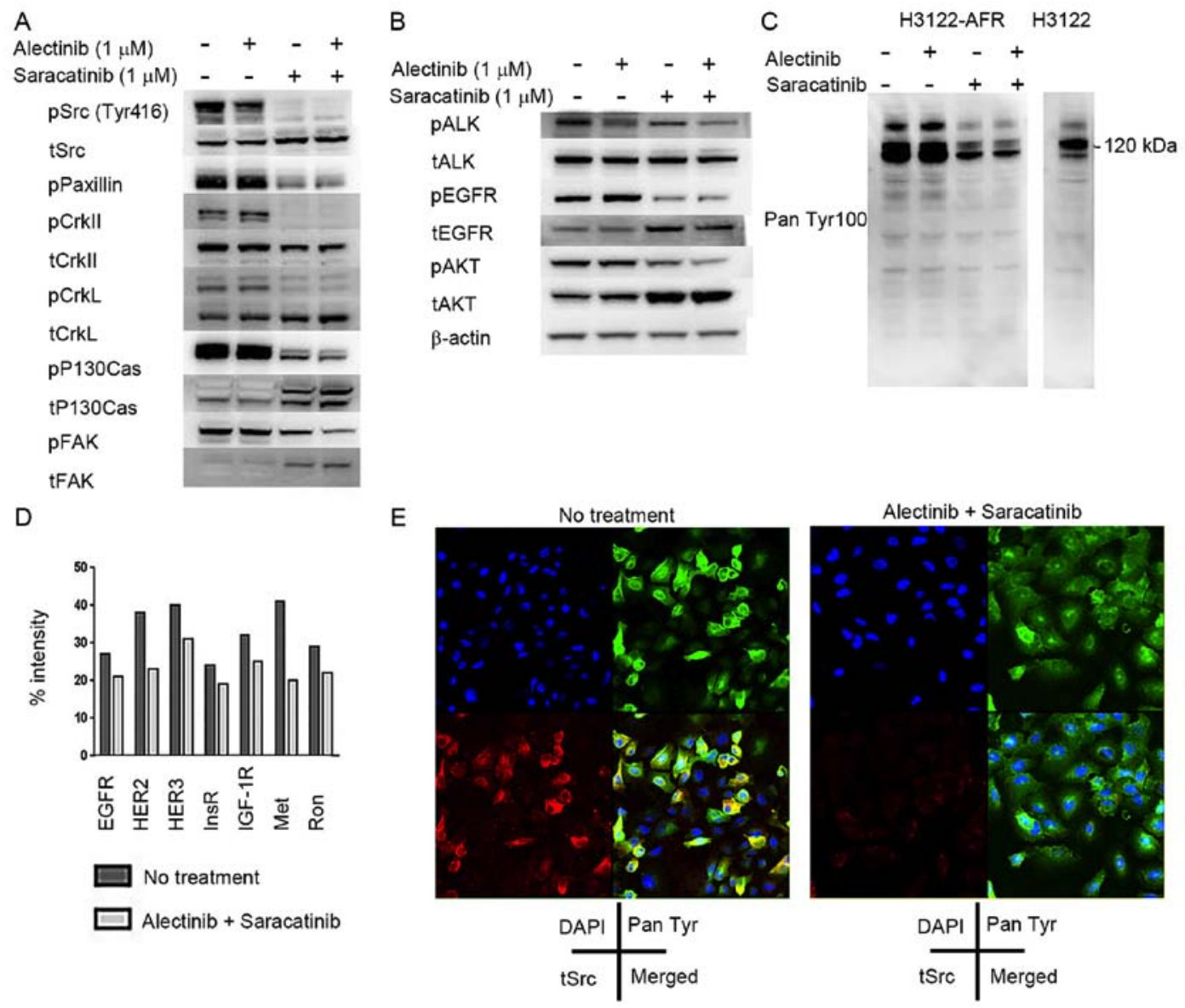

Figure 5. Inhibition of Src overcomes resistance by inhibition of alternative RTKs in H3122-AFR cells. (A and B) Western blot analysis assessing the effect of alectinib $(1 \mu \mathrm{M})$, saracatinib $(1 \mu \mathrm{M})$, or combination treatment on H3122-AFR cells. The expression of Src pathway proteins (A) and ALK, EGFR and downstream PI3K/AKT signaling (B) were assessed. Each cell line was treated with the indicated inhibitors for $24 \mathrm{~h}$. (C) Western blot analysis assessing the effect of alectinib $(1 \mu \mathrm{M})$, saracatinib $(1 \mu \mathrm{M})$, or combination treatment of H3122-AFR on expression of RTKs using a pan Tyr100 antibody. Each cell line was treated with the indicated inhibitors for $24 \mathrm{~h}$. (D) Phospho-RTK array analysis of H3122-AFR cells before and after treatment with alectinib and saracatinib. Changes in phosphorylation levels of multiple RTKs, including components of the EGFR/HER family (EGFR, HER2 and HER3), insulinR (IR) family (InsR and IGF-1R) and HGFR family (Met/HGFR and Ron/MST1R) pathways were assessed in H3122-AFR cells before and after combined treatment with alectinib $(1 \mu \mathrm{M})$ and saracatinib $(1 \mu \mathrm{M})$ for $24 \mathrm{~h}$. (E) Two-color immunofluorescence staining of H3122-AFR cells before and after combined treatment with alectinib $(1 \mu \mathrm{M})$ and saracatinib $(1 \mu \mathrm{M})$ for $8 \mathrm{~h}$.
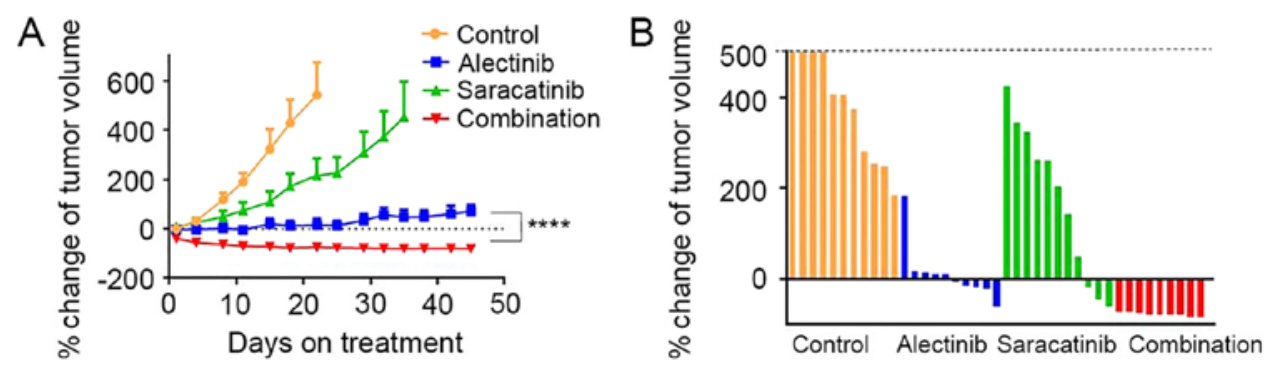

Figure 6. The combined effect of alectinib and saracatinib treatment in H3122-AFR xenograft models. (A) Nude mice bearing H3122-AFR xenografts were treated with vehicle only (Control; yellow, $\mathrm{n}=11$ ), alectinib (blue, $20 \mathrm{mg} / \mathrm{kg}, \mathrm{n}=10$ ), saracatinib (green, $50 \mathrm{mg} / \mathrm{kg}, \mathrm{n}=11$ ), combination (red, alectinib $20 \mathrm{mg} / \mathrm{kg}$ + saracatinib $50 \mathrm{mg} / \mathrm{kg}, \mathrm{n}=9$ ) for the indicated number of days. Average percent change in tumor volume relative to initial tumor volume is shown. The measurements are presented as means \pm SEM. ${ }^{* * * *} \mathrm{P}<0.0001$ for alectinib vs. combination treatment group. (B) Percent change in tumor volume at 22 days after treatment for the individual tumors in each treatment group.

This result showed that the combined use of ALK and Src inhibitors could be effective in different contexts of ALK inhibitor resistance.

Inhibition of Src overcomes resistance by inhibition of alternative RTKs in H3122-AFR cells. Previous reports showed that Src is a common node downstream of multiple resistance pathways $(19,20)$. We confirmed that H3122-AFR cells had higher phosphorylation levels of Src, paxillin and crk II, as well as crkL, P130Cas and FAK compared with H3122 by western blotting (data not shown). We assessed the roles of these Src pathway related proteins in the development of ALK 
inhibitor resistance by studying the combined effect of alectinib and saracatinib on Src signaling in H3122-AFR cells by western blotting. When tumors were treated with saracatinib alone, the phosphorylation levels of Src pathway proteins decreased (Fig. 5A). We also found that EGFR phosphorylation was decreased following treatment with saracatinib alone. On the other hand, ALK phosphorylation levels decreased in response to alectinib alone. Combined treatment with alectinib and saracatinib induced a reduction in AKT phosphorylation (Fig. 5B). In addition, we confirmed that phospho-RTK activity was higher in untreated H3122-AFR cells compared with H3122 cells, and RTK activity decreased in H3122-AFR cells in response to saracatinib alone (Fig. 5C).

Next we analyzed phospho-RTK signaling in H3122 and H3122-AFR cells using human phospho-RTK arrays. These data showed a decrease in ALK phosphorylation in H3122-AFR cells, and an increase in the phosphorylation of multiple RTKs in H3122-AFR cells compared with H3122 cells (data not shown). In addition, there was a decrease in the phosphorylation of multiple RTKs, especially the members of EGFR/HER, insulin receptor (IR) and HGFR families in H3122-AFR cells after combined treatment with alectinib and saracatinib (Fig. 5D).

We also carried out two-color immunofluorescence staining to study the effects of combined ALK and Src inhibition on H3122-AFR cells. These data addressed the expression of phospho-tyrosine proteins and total Src in H3122-AFR cells, and also revealed the co-localization of phospho-tyrosine proteins and Src. Double immunofluorescence staining showed markedly diminished phospho-RTK and Src signals in H3122-AFR cells after combined treatment with alectinib and aaracatinib (Fig. 5E). Taken together, these data indicate that Src inhibition overcomes alectinib resistance in H3122-AFR cells in vitro.

Combined effects of alectinib and saracatinib in H3122-AFR xenograft models. To evaluate the combined effect of alectinib and saracatinib in vivo, H3122-AFR xenograft tumors were established in nude mice. The combined treatment with alectinib and saracatinib resulted in significant tumor regression compared with treatment with each compound alone (Fig. 6A). During the treatment, body weight or individual appearance were not changed. At 22 days after treatment, when the average size of tumors in the control group exceeded $500 \mathrm{~mm}^{3}$, the percent change in tumor volume was significantly decreased by combined treatment, while the volume of some tumors increased in response to monotherapy (Fig. 6B).

\section{Discussion}

We identified the activation of Src signaling as a mechanism of acquired resistance to ALK inhibitors in NSCLC cells. Our data also showed that RTK activation and downstream PI3K/AKT signaling can be effectively blocked by inhibiting Src.

The activation of alternative survival pathways is a common mechanism driving the development of drug resistance in cancer cells. Indeed, the activation of Src is involved in the resistance to the crizotinib used for the treatment of NSCLC and other cancers (11).
iTRAQ-based quantitative proteomic analysis has contributed to the discovery of novel therapeutic targets for cancer $(21,22)$ and recently An et al (12) identified CrkL activation as an NSCLC resistance mechanism by proteomics analysis. However, the role of Src activation in acquired resistance to alectinib, ceritinib and lorlatinib has not been previously reported. We used iTRAQ proteomics and Hsp90-inhibitors to identify chaperone peptides/proteins in ALK resistant cell lines. The screening results revealed that the focal adhesion pathway, involving paxillin and crkII activation, could be involved in ALK resistance. Previous reports identified interactions between $\mathrm{Src}$ and proteins in the focal adhesion pathway $(23,24)$ and in the present study, ALK resistant cells had higher phosphorylation levels of Src-related proteins suggesting that this pathway could be a therapeutic target in ALK resistant cell lines.

Previous studies demonstrated that Src interacts with multiple RTKs and facilitates activation of downstream pathways (25-28). In this study, combined treatment with ALK and Src inhibitors effectively reduced PI3K/AKT mediated survival and proliferation signaling. We showed that dual blockade of ALK and Src inhibited alternative RTKs which were involved in ALK resistance in H3122-AFR cells. Activation of EGFR, IR and HGFR signaling are known mechanisms of resistance to alectinib $(29,30)$. Phospho-RTK arrays and western blotting results confirmed that these bypass signaling pathways were active in H3122-AFR cells compared to H3122 cells. Activation of these alternative survival pathways is likely to be primarily responsible for mediating ALK resistance in H3122-AFR cells because secondary ALK mutations and ALK amplification were not identified in this cell line.

Phospho-RTK arrays also showed that combined treatment with ALK and Src inhibitors led to decreased phosphorylation of multiple RTKs. Although the levels of phospho-RTK inhibition were not dramatic, the efficacy of combined treatment was greater than the efficacy of ALK or Src inhibitors alone in vitro and in vivo. These results suggest that $\mathrm{Src}$ is a common node downstream of multiple resistance pathways in ALK-NSCLCs, which is consistent with previous investigations of RET rearranged NSCLCs and breast cancer $(19,20)$.

Although it is important to validate our findings using clinical specimens, our data suggest that targeting Src signaling may be an effective approach for the treatment of ALK-NSCLCs that are resistant to ALK inhibitors.

\section{Acknowledgements}

The present study was supported by a Grant-in-Aid for Young Scientists [(B) 26860595] from the Ministry of Education, Culture, Sports, Science and Technology.

\section{References}

1. Lee YJ, Kim JH, Kim SK, Ha SJ, Mok TS, Mitsudomi T and Cho BC: Lung cancer in never smokers: Change of a mindset in the molecular era. Lung Cancer 72: 9-15, 2011.

2. Torre LA, Bray F, Siegel RL, Ferlay J, Lortet-Tieulent J and Jemal A: Global cancer statistics, 2012. CA Cancer J Clin 65: 87-108, 2015

3. Oxnard GR, Binder A and Jänne PA: New targetable oncogenes in non-small-cell lung cancer. J Clin Oncol 31: 1097-1104, 2013. 
4. Koivunen JP, Mermel C, Zejnullahu K, Murphy C, Lifshits E, Holmes AJ, Choi HG, Kim J, Chiang D and Thomas R: EML4-ALK fusion gene and efficacy of an ALK kinase inhibitor in lung cancer. Clin Cancer Res 14: 4275-4283, 2008.

5. Kwak EL, Bang YJ, Camidge DR, Shaw AT, Solomon B, Maki RG, Ou SH, Dezube BJ, Jänne PA, Costa DB, et al: Anaplastic lymphoma kinase inhibition in non-small-cell lung cancer. N Engl J Med 363: 1693-1703, 2010.

6. Seto T, Kiura K, Nishio M, Nakagawa K, Maemondo M, Inoue A, Hida T, Yamamoto N, Yoshioka H, Harada M, et al: CH5424802 (RO5424802) for patients with ALK-rearranged advanced non-small-cell lung cancer (AF-001JP study): A single-arm, open-label, phase 1-2 study. Lancet Oncol 14: 590-598, 2013.

7. Shaw AT and Engelman JA: Ceritinib in ALK-rearranged nonsmall-cell lung cancer. N Engl J Med 370: 2537-2539, 2014

8. Katayama R, Shaw AT, Khan TM, Mino-Kenudson M, Solomon BJ, Halmos B, Jessop NA, Wain JC, Yeo AT, Benes $\mathrm{C}$, et al: Mechanisms of acquired crizotinib resistance in ALK-rearranged lung cancers. Sci Transl Med 4: 120ra17, 2012.

9. Yamaguchi N, Lucena-Araujo AR, Nakayama S, de FigueiredoPontes LL, Gonzalez DA, Yasuda H, Kobayashi S, Costa DB and Dual ALK: Dual ALK and EGFR inhibition targets a mechanism of acquired resistance to the tyrosine kinase inhibitor crizotinib in ALK rearranged lung cancer. Lung Cancer 83: 37-43, 2014.

10. Niederst MJ and Engelman JA: Bypass mechanisms of resistance to receptor tyrosine kinase inhibition in lung cancer. Sci Signal 6: re6, 2013.

11. Crystal AS, Shaw AT, Sequist LV, Friboulet L, Niederst MJ, Lockerman EL, Frias RL, Gainor JF, Amzallag A, Greninger P, et al: Patient-derived models of acquired resistance can identify effective drug combinations for cancer. Science 346: 1480-1486, 2014.

12. An R, Wang Y, Voeller D, Gower A, Kim IK, Zhang YW and Giaccone G: CRKL mediates EML4-ALK signaling and is a potential therapeutic target for ALK-rearranged lung adenocarcinoma. Oncotarget 7: 29199-29210, 2016.

13. Sang J, Acquaviva J, Friedland JC, Smith DL, Sequeira M, Zhang C, Jiang Q, Xue L, Lovly CM, Jimenez JP, et al: Targeted inhibition of the molecular chaperone Hsp90 overcomes ALK inhibitor resistance in non-small cell lung cancer. Cancer Discov 3: 430-443, 2013.

14. Katayama R, Khan TM, Benes C, Lifshits E, Ebi H, Rivera VM, Shakespeare WC, Iafrate AJ, Engelman JA and Shaw AT: Therapeutic strategies to overcome crizotinib resistance in non-small cell lung cancers harboring the fusion oncogene EML4-ALK. Proc Natl Acad Sci USA 108: 7535-7540, 2011.

15. Sequist LV, Gettinger S, Senzer NN, Martins RG, Jänne PA, Lilenbaum R, Gray JE, Iafrate AJ, Katayama R, Hafeez N, et al: Activity of IPI-504, a novel heat-shock protein 90 inhibitor, in patients with molecularly defined non-small-cell lung cancer. J Clin Oncol 28: 4953-4960, 2010.

16. Tonack S, Jenkinson C, Cox T, Elliott V, Jenkins RE, Kitteringham NR, Greenhalf W, Shaw V, Michalski CW, Friess $\mathrm{H}$, et al: iTRAQ reveals candidate pancreatic cancer serum biomarkers: Influence of obstructive jaundice on their performance. Br J Cancer 108: 1846-1853, 2013.

17. Chen Z, Sasaki T, Tan X, Carretero J, Shimamura T, Li D, Xu C, Wang Y, Adelmant GO, Capelletti M, et al: Inhibition of ALK, $\mathrm{PI} 3 \mathrm{~K} / \mathrm{MEK}$, and HSP90 in murine lung adenocarcinoma induced by EML4-ALK fusion oncogene. Cancer Res 70: 9827-9836, 2010.
18. Ross PL, Huang YN, Marchese JN, Williamson B, Parker K, Hattan S, Khainovski N, Pillai S, Dey S, Daniels S, et al: Multiplexed protein quantitation in Saccharomyces cerevisiae using amine-reactive isobaric tagging reagents. Mol Cell Proteomics 3: 1154-1169, 2004.

19. Zhang S, Huang WC, Li P, Guo H, Poh SB, Brady SW, Xiong Y, Tseng LM, Li SH, Ding Z, et al: Combating trastuzumab resistance by targeting SRC, a common node downstream of multiple resistance pathways. Nat Med 17: 461-469, 2011.

20. Kang CW, Jang KW, Sohn J, Kim SM, Pyo KH, Kim H, Yun MR, Kang HN, Kim HR, Lim SM, et al: Antitumor activity and acquired resistance mechanism of dovitinib (TKI258) in RET-rearranged lung adenocarcinoma. Mol Cancer Ther 14: 2238-2248, 2015

21. Subbannayya Y, Syed N, Barbhuiya MA, Raja R, Marimuthu A, Sahasrabuddhe N, Pinto SM, Manda SS, Renuse S, Manju HC, et al: Calcium calmodulin dependent kinase kinase 2 - a novel therapeutic target for gastric adenocarcinoma. Cancer Biol Ther 16: 336-345, 2015.

22. Xu J, Li L, Yu G, Ying W, Gao Q, Zhang W, Li X, Ding C, Jiang Y, Wei D, et al: The neddylation-cullin 2-RBX1 E3 ligase axis targets tumor suppressor RhoB for degradation in liver cancer. Mol Cell Proteomics 14: 499-509, 2015.

23. Schlaepfer DD and Hunter T: Evidence for in vivo phosphorylation of the Grb2 SH2-domain binding site on focal adhesion kinase by Src-family protein-tyrosine kinases. Mol Cell Biol 16: 5623-5633, 1996.

24. Schlaepfer DD and Mitra SK: Multiple connections link FAK to cell motility and invasion. Curr Opin Genet Dev 14: 92-101, 2004.

25. Bromann PA, Korkaya $\mathrm{H}$ and Courtneidge SA: The interplay between Src family kinases and receptor tyrosine kinases. Oncogene 23: 7957-7968, 2004.

26. Parsons JT and Parsons SJ: Src family protein tyrosine kinases: Cooperating with growth factor and adhesion signaling pathways. Curr Opin Cell Biol 9: 187-192, 1997.

27. Biscardi JS, Maa MC, Tice DA, Cox ME, Leu TH and Parsons SJ: c-Src-mediated phosphorylation of the epidermal growth factor receptor on Tyr845 and Tyr1101 is associated with modulation of receptor function. J Biol Chem 274: 8335-8343, 1999.

28. Belsches-Jablonski AP, Biscardi JS, Peavy DR, Tice DA, Romney DA and Parsons SJ: Src family kinases and HER2 interactions in human breast cancer cell growth and survival. Oncogene 20: 1465-1475, 2001.

29. Isozaki H, Ichihara E, Takigawa N, Ohashi K, Ochi N, Yasugi M, Ninomiya T, Yamane H, Hotta K, Sakai K, et al: Non-small cell lung cancer cells acquire resistance to the ALK inhibitor alectinib by activating alternative receptor tyrosine kinases. Cancer Res 76: 1506-1516, 2016.

30. Tani T, Yasuda H, Hamamoto J, Kuroda A, Arai D, Ishioka K, Ohgino K, Miyawaki M, Kawada I, Naoki K, et al: Activation of EGFR bypass signaling by $\mathrm{TGF} \alpha$ overexpression induces acquired resistance to alectinib in ALK-translocated lung cancer cells. Mol Cancer Ther 15: 162-171, 2016. 